\title{
Impacts of Adventure-based Counseling Training on the Young Olds
}

\begin{abstract}
$\underline{\text { Abstract }}$
It is commonly believed that Adventure-based Counseling (ABC) training is intended for young people who are active and energetic. The St. James' Settlement (a NGO) in Hong Kong, however, believes that such training can also have positive effects on the young olds (individuals aged 50-65). A group of young old trainees was recruited from the community to help implement related activities to elderly members of this NGO. Their general health condition, levels of life satisfaction, optimism, and self-efficacy were measured before and after the training, and a control group was also recruited. The results show that the ABC training had significant impacts on the life satisfaction, optimism, and self-efficacy levels of the young old trainees. Recommendations are made at the end of the paper.
\end{abstract}

Key Words: Young Olds, Adventure-based Counseling, Life Satisfaction, Self-efficacy. 


\section{Introduction}

With improvements in health services and living style, overall life expectancy is increasing all over the world. Hong Kong in Figures (2009) reveals that the life expectancy for males and females in Hong Kong is 79.4 and 85.5 years, respectively. Conventionally, the retirement age in Hong Kong is 60 or 65, but more people are now choosing to retire earlier, say at 50. This means that some people may live for 20 years or more after retirement.

This increasing cohort of early retirees between the age of 50 and 65 can be expected to have more time, better health, and the wealth to enjoy life after retirement. Some social service centers for the elderly in Hong Kong provide different services for this cohort of retirees, but these services are mostly educational or recreational in nature. The psychological needs of this group cannot be met by the traditional services provided because they are not actually old, but rather young old.

Chronological age is usually used to identify the time at which older adulthood begins and to divide older adults into “young olds” and “old olds” (Austrian, 2008; Fisher, 1993:78). Some gerontologists divide older adults into young olds, those aged from 60 to 74; middle olds, those from 75 to 84; and old olds or the oldest olds, those 85 and over (Atchley \& Barusch, 2004:7). As is commonly practice in Hong Kong, in this study, 'young olds' are defined as early retirees aged 50 to 65 , and this is the age range of the participants.

Schoel et al. (1989) stated that improvements in self-concept and self-esteem can enable a person to find a healthy, confident, constructive and effective way to live. Such a person can develop an admiring attitude toward himself/herself and also start to admire others, which is an important element of positive thinking. If the young olds can also do this, then they can experience a healthy aging process, have high self-esteem and engage in positive thinking.

After retirement, many people lose their roles and their image as competent persons in society. According to the activity theory (Leout'ev, 1981), if the young olds can maintain 
their roles in the society, then they will not only maintain self-confidence, but will also contribute their energies to bettering society.

Strengthening the self-confidence of the young olds is essential in psychologically preparing them for the challenges of aging. Most Adventure-based Counseling (ABC) programs point out that their main goal is to enhance the self-concept of the participants (Schoel et al., 1989). Indeed, the main goal of the ABC program discussed in this paper, which is named "You can shine again” and developed by the St. James' Settlement is to create a challenging environment for the young olds to overcome.

It has to be admitted that most $\mathrm{ABC}$ programs have some requirements in terms of physical ability. Thus, they may not be suitable for people who are too old. As the young old early retirees are not too old or frail, however, they still have the physical abilities required by the programs, and so a number were recruited for this program/study. ABC is widely applied in the young generation. Almost all social service centers for young people in Hong Kong conduct this type of activities. However, the application of ABC to 'old people' is rare both in Hong Kong and overseas. 'Young olds' can be regarded as the population in between late adulthood and early old age.

\section{Adventure-based Counseling (ABC)}

In the early 1900s, the incidence of tuberculosis had grown to a peak in Manhattan State Hospital East. An administrator put the uninfected patients in tents on the hospital grounds because of a limited number of hospital beds. Later, the same hospital tried placing more patients outside, and they found that these patients' general conditions improved. This may be the first documented case in the U.S. of using the outdoors for therapeutic means (Schoel, 2002).

Outward Bound was first established by Kun Hahn, a German physical education teacher who was a firm believer in the learning-by-doing model. Jerry Pieh, the founder of Project 
Adventure in the U.S., agreed with the concepts of Outward Bound and so developed Project Adventure. Both Outward Bound and Project Adventure became popular throughout the United States and other countries, and they have been widely adapted to various settings and professions, including business, education, leadership training and mental health (Berman \& Berman, 1994).

In the Oxford English Dictionary, "adventure" is defined as an activity that has a "certain degree of difficulties," is "strange and new," "challenging” and "different from ordinary life patterns” (Kindersley, 2003). Project Adventure in the United States defines “Adventure-based counseling” as an approach that aims to help participants to achieve growth through a series of programs by utilizing the facilities available (Schoel et al., 1988). The Hong Kong Institute of Adventure Counseling has adopted a broader definition, which aims to help participants grow and any new experiences can be regarded as adventures (Lecture Notes, n.d.).

Adventure-based counseling is a group counseling model that employs a carefully sequenced and processed series of experiential activities to elicit behavioral change (Schoel, 2002). ABC can be divided into different levels according to their complexity, including Adventure Activities, Adventure Training, Adventure Education, Adventure Counseling, and Adventure Therapy (The Hong Kong Federation of Youth Groups, 2008). The prime aim of the adventures is to, through these experiences, bring the participants out from their Comfort Zone to their Growth Zone.

The activities in an ABC program can be classified into low events and high events. Low events are activities carried out near the ground. They require few or no skills, but simple equipments may be needed. High events, in contrast, are mostly carried out well above ground, the settings are more complex (e.g., a rope course), and related skills may need to be learnt. In both types of events, however, participants need to learn and actualize how to 
perform mutual protection activities, and the presence and instruction of qualified trainers are required (Lecture Notes, n.d.).

There are seven essential elements of ABC, including Trust Building, Goal Setting, Challenge/Stress, Peak Experience, Humor/Fun, Problem Solving, and Social Responsibility (Schoel et al., 1988). ABC also has four important components: 1) Adventure Training (allow participants to do something new, so that they can move from the Comfort Zone to the Growth Zone), 2) Experiential Learning (allow participants to learn by doing), 3) Use of the Wilderness Environment (some scholars regard this component as unnecessary), and 4) Individual and Group Counseling (Lee, 2008). ABC is a process that includes briefing, leading, and debriefing, and the ultimate goal is to allow the participants to experience personal growth (Lee, 2009).

“Adventure” activities can be both active and passive. Advocates of the ABC model believe that as long as there is the need to grow, this model can be applied to any targets, including families, couples, children, adolescents/youth, adults and the elderly.

Especially in the "experience” of low and high events, where various activities will be used, the actual help and spiritual support of other group members are necessary to complete certain activities. This is where the participants learn the importance of good interpersonal relationships and how to handle conflicts. In the "debriefing," the counselor leads the participants to reflect on and discuss important issues that arose during the activities. There are five principles that need to be observed in practice: (1) Active participation (of participants), (2) Self-motivation (of participants), (3) Reflection (of participants), (4) Real and meaningful (the experiences), and (5) Appropriate degree of risk (among the activities).

Cheung (2006) has identified seven therapeutic elements of ABC: (1) state of disequilibrium, (2) successful experiences, (3) challenge by choice, (4) facilitation of the process of "here-and-now," (5) role of adventure-based counselor, (6) metaphoric introduction, 
and (7) psychological safety net.

As mentioned, $\mathrm{ABC}$ is widely applied in working with the young generation in Hong Kong. Almost all youth centers in Hong Kong offer these kinds of activities. The ABC approach is also applied to mental health patients in Hong Kong (Adventure Training \& Research Centre, 2009). It is believed that it can be used for people of any classes. However, its application to old people is rare in Hong Kong. References to ABC applications among the elderly are difficult to find locally or overseas.

\section{Physical and Social Activities for Old People}

Some research (Bassey, 2000; Hilleras et al., 1999; Hogan, 2005; McAuley et al., 2000) have examined the relationship between physical activities, social activities, and health status in older adults. It has been found that continued physical activity throughout the adult years positively affects multiple physical capabilities and offsets physical losses due to aging (Bassey, 2000; Hogan, 2005). Data from Sweden (Hilleras et al., 1999), Finland (Ruuskanen \& Ruoppila, 1995), and the United States (McAuley et al., 2000) show that physical activity exhibits a strong positive association with well-being among older adults.

In addition to physical activity, social relationship variables, such as social engagement and social networks, protect older adults' health in many cultures (Berkman et al., 2000; Seeman, 2000). Su and Ferraro (1997) found that social integration is positively correlated with older adults' self-rated health in Fiji, Korea, Malaysia, and the Philippines. In Brazil, it was found that greater social integration and a healthy balance of social exchange have been associated with better mental health in later life and fewer depressive symptoms (Ramos \& Wilmoth, 2003). Thus, evidence shows that physical and social activities are positively

related to the health and social well-being of older adults. This evidence provides a good rationale for organizing $\mathrm{ABC}$ training for early retirees. 


\section{Needs of the Young Olds}

Chronological age is not the only criterion by which to classify the needs of older adults. Young olds are still physically and financially capable because they have just retired from their careers. In fact, they are between late adulthood and early old age. Similar to the other life stages, young olds also need time to get used to this transitional life stage. According to Erikson (1997), the psychological crisis of later adulthood is ego integrity versus despair. He believes that old age is a time for caring for oneself after a lifetime of being cared for or caring for others.

As they age, young olds will face many social changes, including retirement, widowhood, the deaths of friends and relatives, and caregiving for parents, etc. Changes in physical functioning, such as chronic illnesses and activity limitations, are also common. Different from the old olds, however, the young olds may have more resources to tackle these changes, such as better physical health or stable wealth. Retirement remains a great challenge for the young olds, though, if they did not plan well for it.

The needs of the young olds vary according to their health and interests. The range may be quite wide - from individual challenges, such as learning computer skills, to social involvement, such as volunteering in social centers. As they have a lot of time after retirement, they have the space to learn new things and contribute their knowledge to society, instead of just being service recipients. If the young olds can adjust well after retirement, then they can prepare well to face the aging process.

After retirement, the young olds may feel they have lost their roles and image in the society. According to activity theory (Leout'ev, 1981), if the young olds can remain active in the society, then they can also retain their self-confidence and contribute positively to society. When they experience the aging process, they will suffer from worries and uncertain emotions. Some of the young olds may state that they cannot accept becoming 'elderly,' which creates a 
lot of psychological problems, such as depression and anxiety. If we can provide early intervention to them, which will help them to develop resilience, then it will be easier for them to face the challenges in the aging process.

\section{Current Services for Elders in Hong Kong}

There are different kinds of services for the elderly in Hong Kong, such as District Elderly Community Centers (DECCs), Neighborhood Elderly Centers (NECs) and Social Centers for the Elderly (S/Es). The service targets of these centers are mainly those aged 60 or above, and those under 60 cannot register as members.

The scope of services in these elderly centers are different. For example, the S/Es provide more flexible activities because they do not receive any subvention from the Government. They thus have more autonomy in service planning and provision. Because the NECs and DECCs receive financial subvention from the Government, they need to fulfill the basic requirements (Funding Service Agreement) set by the Government in providing their services. Their services include canteen services, drop-in member service, and different activities.

Some DECCs and NECs offer their activities or interest classes to people aged 50 to 60 because they recognize the needs of the young olds. However, the main service targets remain adults 60 or above; and the nature and content of the activities are mainly based on the needs of their members. These centers often hold social and recreational programs, such as Local One-day Tours, Birthday Parties, and Chinese Operas.; or developmental and educational programs, such as learning classes and volunteer services. These activities may not satisfy the needs of the young olds who are physically and mentally more capable than the old olds.

\section{Application of ABC to Young Olds}

No literature on the application of ABC to older adults can be found locally or overseas, although some elderly centers in Hong Kong have applied certain ABC concepts and activities 
to their members. More comprehensive ABC training has yet to be tried.

One DECC in Hong Kong, the St James’ Settlement, invited professional ABC trainers from the Hong Kong Experience Professional Association, China to offer an ABC training course to a group of young olds who had been recruited from the community. This training course included both theories and skills, such as experiential learning, low-event, high-event activities, canoeing, etc. The study reported here is based on the program.

\section{The Study}

This study is based on an ABC training program offered by St. James' Settlement called "You can shine again." After their training, the young old participants were to help the Settlement hold ABC programs for elderly members. Twenty-four young old trainees were recruited from the community to join the training program, and they attended a series of training sessions, as follows (Figure 1).

(Figure 1)

The main aim of this study was to explore the impact of ABC training on various aspects - health, life satisfaction, optimism, and self-efficacy - among the young old trainees.

\section{Definition of 'Young Old'}

According to local convention, 'young old' is defined here as those aged 50-65.

\section{Quantitative Design}

Certified trainers designed a structured ABC training program by integrating theoretical training and experiential learning, which was then administered to the young old trainees.

A pretest and posttest study design with a structured questionnaire was used to examine changes in various aspects of the trainees' health (using the General Health Questionnaire [GHQ12] [Shek, 1989]), levels of life satisfaction (using Life Satisfaction Index [LSI-A]), optimism (using the Life Orientation Test [LOT] to measure optimism [Lai, 1997]), and 
self-efficacy (using the Self-efficacy Scale [SES] [McAvay et al., 1998]) following the training. A control group that was supposed to comprise of young olds with a similar profile to that of the recruits was also invited to participate in the study by the training recruits. The same questionnaire was used for the control group which filled in the questionnaires near the time the posttest was administered to the recruits. The final sample included 24 trainees (the experimental group) and 24 other young olds (the control group).

Health is always of prominent concern among old people, the GHQ was therefore used to measure changes in health status after the ABC training. The Chinese version of the LSI-A was used to measure the elders' overall level of satisfaction with their lives. In the development of social gerontology, research into the life satisfaction of elders has played a prominent role (Sauer \& Warland, 1982). The LSI-A is widely applied in research on the elderly including in Hong Kong and mainland China (Chi \& Boey, 1992, 1994; Chou \& Chi, 1999).

The Chinese-revised LOT (Scheier \& Carver, 1985) was used to measure the optimism level of those in the experimental group. Bandura $(1977,1997)$ proposes that higher expectations for both self-efficacy and outcomes will lead to greater adherence to a given activity. The self-efficacy level of the young old trainees was measured using the Chinese version of the SES.

One strength of the methodology used in this study is that all of those in the experimental group, although initially difficult to recruit, joined the study voluntarily, and thus they were willing to face the challenges of $\mathrm{ABC}$ training. This also meant that both their level of motivation and the response rate were high. A limitation of the methodology used lies with the recruitment of the control group. The control group was recruited by invitation of the participants in the experimental group, and its members were supposed to have a similar personal profile to those in the experimental group. In actual practice, however, there were 
some differences in their demographic backgrounds. The participants in the experimental group had difficulties in finding perfectly matched targets, which meant that most of them just asked their spouses to fill in the questionnaires as control subjects. It was also quite difficult to recruit young olds to join the training program because the concepts of $\mathrm{ABC}$ were new and strange to them, and they were also worried whether they had the necessary physical ability.

\section{Findings and Discussion}

\section{Personal Particulars of the Participants}

The personal particulars of participants in both the experimental and control groups are reported in Table 1. Table 2 reports the statistical differences between the groups.

(Table 1)

(Table 2)

As can be seen from Table 2, there was a statistically significant difference between the two groups in terms of sex $\left[x^{2}(\mathrm{df}=1)=10.08, p=0.001\right]$. There were more females in the control group because most of the males in the experimental group invited their own spouses to be their counterparts in the control group. With regard to age, marital status, education level, living arrangements, health status or financial status, however there was no statistical significant difference between the groups.

Twenty-one (87.5\%) of those in the experimental group were aged below 65, as were all of those in the control group. Nearly $80 \%(19,79.2 \%)$ of those in the experimental group were married, as were two-thirds $(16,66.7 \%)$ of those in the control group. In terms of education, $75 \%$ (18) of the respondents in both groups had attained a secondary school or above level. Less than $20 \%$ (4, 16.6\% for the experimental group; 3, 12.5\% for the control group) of the respondents in both groups lived alone. Nineteen (79.2\%) members of the 
experimental group lived with a spouse with/without children and 18 (75\%) of those in the control group lived under the same conditions. Although chronic illness is common among old people, this was not the case for either group of young olds in this study. In both groups, at least $60 \%$ (15, $62.5 \%$ for the experimental group; $16,66.7 \%$ for the control group) failed to report any chronic illness. Both groups were quite well off financially, with only one participant in the experimental group (and none in the control group) receiving Social Security (CSSA) benefits. Their main source of income was their own savings.

\section{Other Data}

Even though the control group members took the tests only in the posttest period, independent-sampled t-tests were used to investigate any differences in the four scales used in this study to compare the experimental and control groups before the training program began (by using the data from the control group at posttest). No significant differences were found in the scores of any of the four scales, which indicates that the two groups were similar at the beginning of the study. The mean scores and standard deviations are listed in Table 3.

(Table 3)

Prior to training, there were no significant differences between the two groups in the GHQ12 scores (experimental group: $M=20.96, S D=4.20$; control group: $M=23.85$, $S D=6.33$; [t(36)=-1.81, $p=0.079]$ ); the LSI-A scores (experimental group: $\mathrm{M}=64.94, \mathrm{SD}=6.84$; control group: $\mathrm{M}=63.17, \mathrm{SD}=10.25$; $[\mathrm{t}(40)=0.712, p=0.480]$ ); the LOT scores (experimental group: $\mathrm{M}=15.29, \mathrm{SD}=2.68$; control group: $\mathrm{M}=16.96, \mathrm{SD}=3.21$; $[\mathrm{t}(46)=-1.95, p=0.057])$; or the SES scores (experimental group: $\mathrm{M}=38.05, \mathrm{SD}=4.69$; control group: $\mathrm{M}=35.35, \mathrm{SD}=4.83$; $[\mathrm{t}(46)=1.97, p=0.055])$.

After the ABC training program, the posttest results show that there were significant differences between the two groups on all of the scales, with the exception of general health 
scale (Table 4).

(Table 4)

Although there was no statistically significant difference in the GHQ12 scores between the experimental group $(M=22.88, S D=4.66)$ and the control group $(M=23.85, S D=6.33)$ [t(44)=-0.59, $p=0.558]$ in the posttest, there were significant differences between them in the scores for LSI-A (experimental group: $M=50.08, S D=17.30$; control group: $M=63.17$, $\mathrm{SD}=10.25$; $[\mathrm{t}(37)=-3.17, p=0.003]$ ); LOT (experimental group: $\mathrm{M}=14.46, \mathrm{SD}=2.62$; control group: $\mathrm{M}=16.96, \mathrm{SD}=3.21$; [t(46)=-2.96, $p=0.005]$ ); and SES (experimental group: $\mathrm{M}=31.56$, $\mathrm{SD}=5.16$; control group: $\mathrm{M}=35.35, \mathrm{SD}=4.83$; $[\mathrm{t}(46)=-2.63, p=0.012])$.

Thomas and Nelson (1990) stated that the t-test is an appropriate method for measuring changes in attitude and behavior in a training program. These tests were thus used in the pretest and posttest using paired-samples t-tests to compare the differences between the mean scores.

The paired two-tailed t-tests used to compare the means and SD of the pretest and posttest scores for the experimental group showed significant differences in the LSI-A and SES (Table 5).

(Table 5)

There was no significant difference in the GHQ scores between Time 1 ( $M=20.96$, $\mathrm{SD}=4.20)$ and Time $2(\mathrm{M}=22.88, \mathrm{SD}=4.66)$ [t(23)=-1.58, $p=0.129]$, although there was a statistically significant difference in the LSI-A scores between the two time periods (Time 1: $\mathrm{M}=64.96, \mathrm{SD}=6,84$; Time 2: $\mathrm{M}=50.08, \mathrm{SD}=17.30$; $[\mathrm{t}(23)=3.75, p=0.001])$. Similarly, there was no significant difference in the LOT scores between Time $1(\mathrm{M}=15.29, \mathrm{SD}=2.68)$ and Time $2(\mathrm{M}=14.46, \mathrm{SD}=2.62)[\mathrm{t}(23)=1.13, p=0.269]$, but there was a significant difference in 
the SES scores between Time $1(\mathrm{M}=38.05, \mathrm{SD}=4.69)$ and Time $2(\mathrm{M}=31.56, \mathrm{SD}=5.16)$ $[\mathrm{t}(23)=4.58, p=0.0001]$.

For the experimental group, an independent-sampled t-test was also used to determine whether there were any difference(s) in the four scales between the sexes before and after the training program. In terms of general health, a significant difference was found between males $(\mathrm{M}=20.08, \mathrm{SD}=2.575)$ and females $(\mathrm{M}=21.83, \mathrm{SD}=5.340)$ after training $[\mathrm{t}(22)=-2.117$, $p=0.046]$. The scores for the female trainees saw significantly more improvement than did those of their counterparts. This may be because the female trainees perceived themselves to have better health after the training as they were able to complete the difficult tasks if required. There was also a significant difference in the LSI-A scores between males $(\mathrm{M}=68.08$, $\mathrm{SD}=5.616)$ and females $(\mathrm{M}=61.83, \mathrm{SD}=6.699)$ before the training $[\mathrm{t}(22)=2.477, p=0.021]$. The life satisfaction level of the latter was higher before the training, although males and females have similar scores after the training. This may be because most of the male trainees had been in paid work before retirement, whereas most of the female trainees had either been retired for a longer period of time or had been housewives before the training. Thus, the life satisfaction of the female group was superior to that of the male group before the training because the former had grown more used to non-working life (retirement) than the latter. There was no statistically significant difference between the sexes in the LOT and SES scores either before or after the training (Table 6).

(Table 6)

Other than sex, no significant differences were identified among the four scales in terms of the participants’ personal particulars before and after the training program.

The application of ABC training in a setting of older adults is rare both in Hong Kong and elsewhere. The present study reveals that it can be effectively applied to young olds and has 
positive and significant effects on various aspects of their lives. In this study, independent-sampled t-tests were used to investigate differences between the experimental group and the control group in their scores in the four scales. No significant such differences were found between two groups before the $\mathrm{ABC}$ training. After the training, comparisons were made between the two groups in terms of their general health condition and levels of life satisfaction, optimism and self-efficacy, and significant differences were found in the latter three.

When comparing the trainees, i.e. those within the experimental group, before and after the ABC training, significant differences were found in life satisfaction and self-efficacy levels but not in optimism and general health.

The young old trainees realized significant improvement in some aspects of life satisfaction after joining the ABC training program. After retirement, young olds may feel they have lost their role as employees. Empty nest syndrome may cause them to feel even more lost or confused about their role and identity. The young old trainees in this study not only received $A B C$ training, but they were also needed to provide voluntary services to members of different units of the St. James' Settlement. During this process, they were able to find a new identity for themselves. These young old trainees not only tried something new, but they also became volunteers, thus allowing them to actualize what they had learnt. Their level of satisfaction toward life therefore improved after the training program.

With regard to the aspects of self-efficacy, there were significant differences both within the experimental group before and after training and between groups. The self-efficacy level of the young old trainees significantly improved after they joined the ABC training program.

This training program presented quite a challenge for all of the young old trainees because none had experienced or even heard of this kind of program before. However, all of them made the choice to commit themselves to the training program and completed all of the tasks 
required. Some of them did not initially feel they had enough confidence to complete the tasks; however, all of them overcome the associated difficulties with encouragement from their peers. This may be one of the reasons the overall self-efficacy level of the young old trainees improved after they received the ABC training.

The optimism level of the trainees had also improved relative to the control group. Optimism is a positive attitude towards what is happening around us. The young old trainees may have had a very positive experience during the training process. They experienced the support, care and concern of the peers, even when they were unsuccessful in completing the training tasks. Thus, the positive atmosphere and the support of their peers may have improved the trainees’ overall attitude toward life.

No significant difference was found within the experimental group in terms of general health before and after the training. This may be because one's health condition is generally quite stable compared with the other three variables which are more easily affected or changed by joining a program such as ABC training.

\section{Limitations of the Study}

(1) It was also quite difficult to recruit young olds to join the training program because the concepts of $\mathrm{ABC}$ were new and strange to them, and they were also worried whether they had the necessary physical ability.

(2) Involvement in other kinds of activities of the participants may bring about positive effects to their life satisfaction and self-efficacy, and we do not know the situation.

(3) One of the limitations concerns about the methodology used. The control group was recruited by invitation of the participants in the experimental group, and its members were supposed to have a similar personal profile to those in the experimental group. In actual practice, however, there were some differences in their demographic backgrounds. The participants in the experimental group had difficulties in finding perfectly matched targets, 
most of them just asked their spouses to fill in the questionnaires as control subjects.

\section{Implications of the Study}

The general public generally stereotypes the elderly as weak and lacking in energy, old, and stubborn. However, this study shows that older people - the young olds in this case - can be energetic and dynamic and handle challenging tasks just like their younger counterparts. The service providers of existing elderly services will draw insights from this study. These service provides may not currently be meeting the needs and lifestyles of the type of recipients, who may now perceive themselves to be service users. These service users may want to participate more actively in existing service units.

This study also has implications for the content of service programs or activities for the young olds. This cohort wants something new, challenging, and dynamic, not merely talks, health checks, picnics, etc. If we do not modify or re-package the content or style of today's services, then the young olds will not be willing to devote their time to elderly centers or become members.

As the concepts and format of ABC training programs are quite new in the elderly field, they can be further promoted to further prove their positive effects. As the sample size of the present study was rather small, the power of its generalizability may not be great. Although involvement of other kinds of activities, such as volunteering, may bring about positive effects to life satisfaction and self-efficacy, it is believed that the changes in the experimental group are largely due to the participants' involvement in the ABC program. Further studies on the use of $\mathrm{ABC}$ training for old people are recommended to establish evidence of its positive effects. 


\section{References}

Adventure Training \& Research Centre (2009). http://www.adventure.com.hk/profile.htm

Atchely, R.C. and Barusch, A.S. (2004). Social Forces and Aging: An Introduction to Social Gerontology. Belmont, Calif: Wadsworth.

Austrian, S.G. (2008). Developmental Theories through the Life Cycle. New York: Columbia University Press.

Bandura, A. (1977). Self-efficacy: Towards a unifying theory of behavioral change. Psychological Review. Vol.84:191-215.

Bandura, A. (1997). Self-efficacy. New York: Freeman.

Bassey, E.J. (2000). The benefits of exercise for the health of older people. Review of Clinical Gerontology. Vol.10:17-31.

Berkman, L.F., Glass,T., Brissette, I. \& Seemen, T.E. (2000). From social integration to health: Durkheim un the new millennium. Social Science \& Medicine. Vol.51:843-57.

Berman, J.D. \& Berman, D.S. (1994). Two-year follow-up report for the wilderness therapy program. Journal of Experiential Education. Vol.17:48-50.

Cheung, K.W. (2006). Adventure-based Counseling as a Therapeutic Intervention with Youth- at-risk in Hong Kong: The Views of Senior Practitioners. (MSW Thesis) Hong Kong: HKU.

Chi, I. \& Boey, K.W. (1992). Validation of Measuring Instruments of Mental Health Status of the Elderly in Hong Kong (Resource Paper Series No. 17). Hong Kong: Department of Social Work and Social Administration, HKU.

Chi, I. \& Boey, K.W. (1994). A Mental Health and Social Support Study of the Old-Old in Hong Kong. Hong Kong: Department of Social Work and Social Administration, HKU.

Chou, K.L. \& Chi, I. (1999). Determinants of life satisfaction among Chinese older adults: A longitudinal study. Aging and Mental Health: An International Journal. Vol.3:327-34.

Erikson, E.H. (1997). The Life Cycle Completed. New York: W.W. Norton, c1977.

Fisher, J. (1993). A framework for describing developmental change among older adults. Adult Education Quarterly. Vol.43 (2):76-89.

Hilleras, P.K., Jorm, A.F., Herlitz, A. \& Winblad, B. (1999). Activity patterns in very old people; A survey of cognitively intact subjects aged 90 years or older. Age and Ageing. Vol.28:147-52. 
Hogan, M. (2005). Physical and cognitive activity and perceived self-efficacy in older adults. Adultspan. Vol.2:29-43.

Hong Kong Government (2009). Hong Kong in Figures. Hong Kong: HKSAR Government.

Kindersley, D. (2003). Oxford English Dictionary. London: Oxford University Press.

Lai, J.C.L. (1997). Relative predictive power of the optimism versus the pessimism index of a Chinese version of the life orientation test. The Psychological Record. Vol.47(3):399-410.

Lecture Notes (n.d.). Course on Adventure-based Counseling: Theory and Practice. Hong Kong: Hong Kong University.

Lee, F.W.L. (2009). Adventure-based counselling (ABC) approach: Working with young people in a world of conflicts. International Journal of Child Health and Human Development. Vol.2(4):403-8.

Leout'ev, A. (1981). Problems of the Development of Mind. Moscow: Progress Press.

McAuley, E., Blissmer, B., Marquez, D.X., Jerome, G..J., Kramer, A.F. \& Katula, J. (2000). Social relations, physical activity, and well-being in older adults.

Preventive Medicine. Vol.31:608-17.

Ramos, M. \& Wilmoth, J. (2003). Social relationships and depressive symptoms among older adults in southern Brazil. Journal of Gerontology: Social Sciences. 58B, S253-61.

Ruuskanen, M. \& Ruoppila, I., (1995). Physical activity and psychological well-being among people aged 65 to 84 years of age. Age and Ageing. Vol.24:292-96.

Sauer, W.J. \& Warland, R. (1982). Morale and life satisfaction. In D.J. Mangen \& W.A. Peterson (eds.) Research Instruments in Social Gerontology (Volume 1): Clinical and Social Psychology. Minneapolis, M.N.: University of Minnesota Press, (pp.195-240).

Scheier, M.F. \& Carver, C.S. (1985). Optimism, coping and health: Assessment and implications of generalized outcome expectancies. Health Psychology. Vol.4:219-47.

Schoel, J. (2002). Exploring Islands of Healing: New Perspectives on Adventure-based Counseling. Beverly, Mass: Project Adventure.

Schoel, J., Prouty, D. \& Radcliffe, P. (1988). Islands of Healing: A Guide to Adventure-based Counseling. Hamilton, MA: Project Adventure..

Seemem, T.E. (2000). Health promoting effects of friends and family health outcomes in older adults. American Journal of Health Promotion. Vol.14:362-70.

Shek, D.T.L. (1989). Validity of the Chinese Version of the General Health Questionnaire. Journal of Clinical Psychology. Vol.45(6):890. 
Su, Y. \& Ferraro, K.F. (1997). Social relations and health assessments among older people: Do the effects of integration and social contributions vary cross-culturally? Journal of Gerontology: Social Sciences. 52B, S27-36.

The Hong Kong Federation of Youth Groups (2008). Adventure Training: Idea and Practice. Hong Kong: The Hong Kong Federation of Youth Groups.

Thomas, J.R. \& Nelson, J.K. (1990). Research Methods in Physical Activity. (2/e) New York: Human Kinetics Books.

李永年 (2008)，歷奇為本青少年工作，＜東區積極人生計劃青少年行為模式介人 論叢，香港中華基督教青少年柴灣會所，香港樹仁大學社會工作學系(編)， 香港。(頁 3 至 16) [Lee, F.W.L. (2008). Adventure-based Youth Work. Youth Work Models and Interventions - Positive Life Plan Project of Eastern District. Hong Kong: Chai Wan Centre, Chinese YMCA and Department of Social Work, Hong Kong Shue Yan University. (P.3-16)]

香港小童群益會編輯小組 (2001)，＜歷奇為本輔導概念與實踐〉，香港小童群益 會, 香港 。[Editorial Group, The Boys’ and Girls' Clubs Association of Hong Kong (2001). Adventure-based Counseling: Concepts and Practice. Hong Kong: BGCA of HK.]

Figure 1: Training Program

\begin{tabular}{|c|c|}
\hline \multicolumn{2}{|c|}{ ABC Training Programs } \\
\hline Content & Frequency (3 hours/session) \\
\hline Theory of ABC & 6 Sessions \\
\hline Canoeing (One-star) Training Course & 1-day Training \\
\hline Low Event, High Event \& Sports Climbing & 1-day Training \\
\hline Hiking \& Overnight Camp & 2-day Overnight Training \\
\hline Water Activities & 1-day Training \\
\hline
\end{tabular}


Table 1: Personal Particulars of Respondents

\begin{tabular}{|c|c|c|c|}
\hline \multicolumn{2}{|c|}{$\begin{array}{rr}\text { Particulars } \\
\end{array}$} & \multirow{2}{*}{$\begin{array}{c}\frac{\text { Experimental Group }}{\text { Frequency (\%) }} \\
12(50.0)\end{array}$} & \multirow{2}{*}{$\begin{array}{c}\text { Control Group } \\
\text { Frequency (\%) } \\
2(8.3) \\
\end{array}$} \\
\hline Sex & Male & & \\
\hline & Female & $12(50.0)$ & $22(91.7)$ \\
\hline \multirow{4}{*}{ Age } & 50-54 & $7(29.2)$ & $3(12.5)$ \\
\hline & $55-59$ & $7(29.2)$ & $14(58.3)$ \\
\hline & $60-64$ & $7(29.2)$ & $7(29.2)$ \\
\hline & 65 & $3(12.5)$ & $0(0.0)$ \\
\hline \multirow{4}{*}{$\begin{array}{c}\text { Marital } \\
\text { Status }\end{array}$} & Single & $1(4.2)$ & $4(16.7)$ \\
\hline & Married & $19(79.2)$ & $16(66.7)$ \\
\hline & Separated/Divorced & $1(4.2)$ & $4(16.7)$ \\
\hline & Widowed & $3(12.5)$ & $0(0.0)$ \\
\hline \multirow{4}{*}{$\begin{array}{l}\text { Edu. } \\
\text { Level }\end{array}$} & Tertiary & 4 (16.7) & $1(4.2)$ \\
\hline & Secondary & $14(58.3)$ & $17(70.8)$ \\
\hline & Primary & $5(20.8)$ & $5(20.8)$ \\
\hline & Know some Chinese characters & $1(4.2)$ & $1(4.2)$ \\
\hline \multirow{4}{*}{$\begin{array}{l}\text { Living } \\
\text { Arrange- } \\
\text { ments }\end{array}$} & Alone & $4(16.6)$ & $3(12.5)$ \\
\hline & With spouse & $6(25.0)$ & $9(37.5)$ \\
\hline & With spouse \& child(ren) & $13(54.2)$ & $9(37.5)$ \\
\hline & Others & $1(4.2)$ & $3(12.5)$ \\
\hline \multirow{3}{*}{$\begin{array}{c}\text { No. of } \\
\text { Chronic } \\
\text { Illnesses }\end{array}$} & No & $15(62.5)$ & $16(66.7)$ \\
\hline & One & $8(33.3)$ & $6(25.0)$ \\
\hline & Two & $1(4.2)$ & $2(8.3)$ \\
\hline \multirow{5}{*}{$\begin{array}{l}\text { Financial } \\
\text { Status } \\
\text { (Depends } \\
\text { On) }\end{array}$} & Savings & 11 (45.8) & 14 (58.3) \\
\hline & Pension & $7(29.2)$ & $7(29.2)$ \\
\hline & Social Security & $1(4.2)$ & $0(0.0)$ \\
\hline & Family support & $4(16.6)$ & $3(12.5)$ \\
\hline & Savings + Pension & $1(4.2)$ & $0(0.0)$ \\
\hline & TOTAL - N (\%) & $24(100.0)$ & $24(100.0)$ \\
\hline
\end{tabular}

Table 2: Statistical Figures of the Personal Particulars among the Experimental and Control Groups

\begin{tabular}{|c|c|c|c|}
\hline Personal Particulars & $\boldsymbol{x}^{2}$ & df & $\boldsymbol{p}$ \\
\hline \hline Sex & 10.08 & 1 & 0.001 \\
\hline Age & 0.820 & 1 & 0.365 \\
\hline Marital Status & 0.929 & 1 & 0.330 \\
\hline Education level & 0.070 & 1 & 0.792 \\
\hline Living arrangements & 0.222 & 1 & 0.638 \\
\hline Health status & 0.171 & 1 & 0.679 \\
\hline Financial status & 1.021 & 1 & 0.312 \\
\hline
\end{tabular}


Table 3: Mean Scores on the Four Scales of the Two Groups before the Training

\begin{tabular}{|c|c|c|c|c|c|c|}
\hline \multirow{2}{*}{ Scale } & \multicolumn{3}{|c|}{ Experimental Group } & \multicolumn{3}{c|}{ Control Group } \\
\cline { 2 - 7 } & $\mathrm{N}$ & Mean & S.D. & N & Mean & S.D. \\
\hline General Health & 24 & 20.96 & 4.20 & 22 & 23.85 & 6.33 \\
\hline Life Satisfaction & 24 & 64.96 & 6.84 & 24 & 63.17 & 10.25 \\
\hline Optimism & 24 & 15.29 & 2.68 & 24 & 16.96 & 3.21 \\
\hline Self-efficacy & 24 & 38.05 & 4.69 & 24 & 35.35 & 4.83 \\
\hline
\end{tabular}

Table 4: Statistical Data on the Four Scales of the Two Groups at Posttest (After the Training)

\begin{tabular}{|c|c|c|c|c|c|c|c|}
\hline \multirow{2}{*}{ Scale } & \multicolumn{3}{|c|}{ Experimental Group } & \multicolumn{3}{c|}{ Control Group } & \multirow{2}{*}{$\boldsymbol{p}$} \\
\cline { 2 - 7 } & $\mathrm{N}$ & Mean & S.D. & $\mathrm{N}$ & Mean & S.D. & \\
\hline \hline General Health & 24 & 22.88 & 4.66 & 24 & 23.85 & 6.33 & 0.558 \\
\hline Life Satisfaction & 24 & 50.08 & 17.30 & 24 & 63.17 & 10.25 & 0.003 \\
\hline Optimism & 24 & 14.46 & 2.62 & 24 & 16.96 & 3.21 & 0.005 \\
\hline Self-efficacy & 24 & 31.56 & 5.16 & 24 & 35.35 & 4.83 & 0.012 \\
\hline
\end{tabular}

Table 5: Some Statistical Data on the Experimental Group before and after Training

\begin{tabular}{|c|c|c|c|c|c|}
\hline \multirow{2}{*}{ Scale } & \multicolumn{2}{|c|}{$\begin{array}{c}\text { Before Training } \\
\text { (Time 1) }\end{array}$} & \multicolumn{2}{c|}{$\begin{array}{c}\text { After Training } \\
\text { (Time 2) }\end{array}$} & \multirow{2}{*}{$p$} \\
\cline { 2 - 5 } & \multicolumn{2}{|c|}{$\mathrm{N}=24$} & \multicolumn{2}{c|}{$\mathrm{N}=24$} & \\
\cline { 2 - 5 } & Mean & S.D. & Mean & S.D. & 0.129 \\
\hline General Health & 20.96 & 4.20 & 22.88 & 4.66 & 0.001 \\
\hline Life Satisfaction & 64.96 & 6.84 & 50.08 & 17.30 & 0.269 \\
\hline Optimism & 15.29 & 2.68 & 14.46 & 2.62 & 0.0001 \\
\hline Self-efficacy & 38.05 & 4.69 & 31.56 & 5.16 & \\
\hline
\end{tabular}

Table 6: Some Statistical Comparison of the Four Scales by Experimental Group by Sex before and after ABC Training

\begin{tabular}{|c|c|c|c|c|c|c|c|c|}
\hline \multirow{2}{*}{ Scale } & & \multicolumn{3}{|c|}{ Males } & \multicolumn{3}{c|}{ Females } & \multicolumn{1}{c|}{} \\
\cline { 3 - 9 } & & $\mathrm{N}$ & Mean & S.D. & $\mathrm{N}$ & Mean & S.D. & $p$ \\
\hline \multirow{3}{*}{ General Health } & Before & 12 & 20.08 & 2.575 & 12 & 21.83 & 5.340 & 0.367 \\
\cline { 2 - 9 } & After & 12 & 21.00 & 3.693 & 12 & 24.75 & 4.901 & 0.046 \\
\hline \multirow{2}{*}{ Life Satisfaction } & Before & 12 & 68.08 & 5.616 & 12 & 61.83 & 6.699 & 0.011 \\
\cline { 2 - 9 } & After & 12 & 50.67 & 18.816 & 12 & 49.50 & 16.468 & 0.873 \\
\hline \multirow{2}{*}{ Optimism } & Before & 12 & 15.00 & 2.174 & 12 & 15.58 & 3.175 & 0.501 \\
\cline { 2 - 9 } & After & 12 & 13.75 & 1.658 & 12 & 15.17 & 3.243 & 0.192 \\
\hline \multirow{2}{*}{ Self-efficacy } & Before & 12 & 39.20 & 4.917 & 12 & 36.90 & 4.346 & 0.212 \\
\cline { 2 - 9 } & After & 12 & 31.13 & 5.886 & 12 & 31.98 & 4.535 & 0.696 \\
\hline
\end{tabular}

